\title{
(C) OPEN ACCESS \\ Is lower hip range of motion a risk factor for groin pain in athletes? A systematic review with clinical applications
}

\author{
Igor Tak, 1,2 Leonie Engelaar, ${ }^{3}$ Vincent Gouttebarge, ${ }^{4}$ Maarten Barendrecht, ${ }^{5,6}$ \\ Sylvia Van den Heuvel, ${ }^{5}$ Gino Kerkhoffs, ${ }^{7}$ Rob Langhout, ${ }^{8}$ Janine Stubbe, ${ }^{9,10}$ \\ Adam Weir ${ }^{11}$
}

- Additional material is published online only. To view please visit the journal online (http://dx.doi.org/10.1136/ bjsports-2016-096619).

For numbered affiliations see end of article.

\section{Correspondence to} Igor Tak, Manual Therapy and Sports Rehabilitation, Physiotherapy Utrecht Oost, Bloemstraat 65 D, Utrecht 3581 WD, The Netherlands; igor.tak@gmail.com

Accepted 27 February 2017 Published Online First 21 April 2017
CrossMark

To cite: Tak I, Engelaar L, Gouttebarge $\mathrm{V}$, et al. $\mathrm{Br} J$ Sports Med

2017;51:1611-1621.

\begin{abstract}
Background Whether hip range of motion (ROM) is a risk factor for groin pain in athletes is not known. Objectives To systematically review the relationship between hip ROM and groin pain in athletes in crosssectional/case-control and prospective studies.

Study design Systematic review, prospectively registered (PROSPERO) according to PRISMA guidelines. Methods Pubmed, Embase, CINAHL and SPORTDiscus were systematically searched up to December 2015. Two authors performed study selection, data extraction/analysis, quality assessment (Critical Appraisal Skills Programme) and strength of evidence synthesis.
\end{abstract}

Results We identified seven prospective and four case-control studies. The total quality score ranged from $29 \%$ to $92 \%$. Heterogeneity in groin pain classification, injury definitions and physical assessment precluded data pooling. There was strong evidence that total rotation of both hips below $85^{\circ}$ measured at the pre-season screening was a risk factor for groin pain development. Strong evidence suggested that internal rotation, abduction and extension were not associated with the risk or presence of groin pain.

Conclusion Total hip ROM is the factor most consistently related to groin pain in athletes. Screening for hip ROM is unlikely to correctly identify an athlete at risk of developing groin pain because of the small ROM differences found and poor ROM measurement properties.

\section{INTRODUCTION}

Groin pain is common in sports involving explosive movements, directional changes, repeated kicking and body contact. ${ }^{1}$ The aetiology of groin pain is unclear and probably multifactorial. ${ }^{2}$ Seven systematic reviews ${ }^{3-9}$ have focused on factors associated with groin pain in athletes. Lower hip range of motion (ROM) was a risk factor in four systematic reviews, ${ }^{4-9}$ but not in two others. ${ }^{36}$ Mosler et al ${ }^{5}$ studied factors that differentiated athletes with and without hip and groin pain and found lower hip ROM to be associated with its presence.

A recent international agreement reported that the hip can be an important cause of groin pain in athletes. ${ }^{1}$ The interference of hip-related pathology, hip ROM and groin pain was not examined in these reviews. Additionally, there is no clear understanding of the paradigm of decreased hip ROM in relation to groin pain. ${ }^{1011}$
No published prevention or treatment programmes for groin pain in athletes focus specifically on hip ROM. ${ }^{13}$ A recent meta-analysis of seven randomised trials on preventing groin injuries in athletes showed a lack of efficacy. ${ }^{12}$ These prevention programmes mainly consisted of active exercise and did not examine hip ROM at baseline or follow-up. A review appraising existing literature on hip ROM measures and their relation to groin pain would assist in the planning of new preventative strategies and making adequate choices in study designs.

The primary aim of this review was assess whether there was a relationship between hip ROM and groin pain in athletes. The secondary aim was to guide clinicians and researchers in interpreting the findings on the relationship between hip ROM and groin pain. The key research question was, is there a relationship between hip ROM and the presence of groin pain in athletes?

\section{METHODS}

This systematic review was conducted in accordance with the PRISMA (Preferred Reporting Items for Systematic Reviews and Meta-Analysis) guidelines. The protocol for this review was registered at the PROSPERO register (website; http://www. crd.york.ac.uk/PROSPERO) for systematic reviews under registration number CRD42015017666.

\section{Search strategy}

Before this systematic review the Cochrane Database of Systematic Reviews, MEDLINE and PEDro were searched for systematic reviews on groin pain in athletes involving hip ROM to ensure that a similar study had not already been conducted. No date restrictions were applied and all databases were searched in full up to 1 August 2015 when this review process started.

To identify studies that met the inclusion criteria, a search was conducted on 1 December 2015 in the electronic databases Pubmed, Embase, CINAHL and SPORTDiscus without any date restriction. A combination of the following keywords and their synonyms was used: groin pain, hip ROM, risk factors (see online supplementary appendix 1 for the full search strategy). Cross-references from previous reviews and all retained articles that fulfilled the inclusion criteria were screened for possible relevance. Additionally, three experts in the field were asked whether they had any relevant references available from books or other sources. All 
results were entered in Reference Manager (Thomson Reuters, Philadelphia, USA). Duplicates were removed.

\section{Selection of studies}

Two reviewers (LE and IT) independently reviewed all obtained titles and abstracts to determine possible eligibility. They checked full-text versions of all the retained articles and screened reference lists of these studies and the systematic reviews already identified, for other relevant citations. Full-text screening was then performed according to the eligibility criteria. The selection status of each retained article was discussed and disagreements were resolved by consensus. A third reviewer (AW) was available to discuss ongoing disagreement. A final list of articles for further detailed analysis was created.

\section{Eligibility criteria}

Studies were considered eligible for this review if data were presented on hip ROM in athletes in a study evaluating risk of developing groin pain (prospective longitudinal study), OR when comparing athletes with and without groin pain (cross-sectional/ case series study). Groin pain could be described according to the numerous past different definitions in the literature. ${ }^{1}$

A study was only included if it fulfilled the following criteria:

a. an original study, published in English, German, French or Dutch;

b. an observational (prospective) cohort, cross-sectional or case-control study;

c. studying athletes as the population of interest;

d. studying groin pain as a variable;

e. studying hip $\mathrm{ROM}$ as a variable;

f. presenting statistical data analyses of the relationship between dependent and independent variables (groin pain and hip ROM).

This review aimed to assist clinicians working with athletes who might be at risk for, or have already developed, groin pain. Studies on hip and/or groin pain caused by known hip conditions were excluded as being outside the scope of this review. Intervention studies were excluded, as were studies on cadavers or animals.

\section{Data extraction, synthesis and analysis}

Two reviewers (LE and IT) extracted the following data, using a standardised form:

- definitions of groin pain and the accompanying injury criteria (used terms, specifications of groin pain and (physical) examination criteria);

- onset of pain;

- time of existing complaints;

- time loss;

- study setting (sports type and level, gender, country);

- study setting and design;

- details of ROM assessment (movement directions, body position, measurement device, reporting of data in appropriate Système International units, ${ }^{13}$ definition of end ROM and the number and qualification of assessors).

The study results and outcomes are presented as the number of participants, injuries and (injured) hips, including percentage. It is reported whether injured players or injured hips were used for analyses and which data were provided (per side, for all hips or bilateral hips (BH) as sum scores). As a previous injury increases the risk of a re-injury, any reporting of re-injuries and methodological/statistical considerations (whether correction was needed or not) are presented. Data are analysed descriptively. For the studies that supplied adequate continuous data, means and SD or SE of means are presented. For dichotomous data, ORs/RR with matching $95 \%$ CIs are presented. Mean differences (MD) for each ROM movement are calculated and presented, rounded off to whole numbers as most measurement tools have $1^{\circ}$ increments.

\section{Risk of bias assessment}

We used the Critical Appraisal Skills Programme (CASP, 2014, www.casp-uk.net) check list to assess the risk of bias in included studies, and specifically adapted ${ }^{14}{ }^{15}$ (LE, IT, MB) it for our systematic review. The criteria list contains items on information, validity and/or precision in the following categories: study objective, study population, exposure measurement, assessment and analysis of the outcome and data presentation (see online supplementary appendix 2 for the full criteria list).

Two independent reviewers (LE and IT) rated each study as 'positive' (+) if it included an item, 'negative' $(-)$ if it did not include an item, 'non-applicable' (NA) if that item was not applicable to that particular study. When no clear information was present on this item a 'negative' $(-)$ was scored. The reviewers compared their results and in cases of disagreement, consensus on each item was reached in a meeting. Absolute values and level of agreement (Cohen's $\kappa$ ) are presented. The number of items that were rated positively was divided by the total achievable (applicable items only) score to provide a 'quality score'. The studies were ranked as a percentage of the maximum achievable score, and, relative to this total score, categorised as scoring high or low according to the CASP criteria. ${ }^{16} \mathrm{~A}$ high score, thus a low risk of bias study, was a study that scored positively for $>50 \%$ of the validity/precision items on the methodological quality list. A low score, referring to a high risk of bias study, was one that scored positively for $\leq 50 \%$ of the validity/precision items. ${ }^{14}{ }^{17}$ Quality scores were obtained for each study type and overall. All studies were checked for reporting on conflicts of interest. ${ }^{18}$

\section{Item assessment}

Item assessment was performed by calculating the ratio of positively scored items/negatively scored items for each CASP item over all the studies. When no negative score was obtained a 'maximum' score was assigned and when no positive score was obtained a 'minimum' score was assigned. This was done in order to provide an insight into which items, in general, had low or high scores among the studies included.

\section{Strength-of-evidence assessment}

The strength of evidence for hip ROM as a potential risk factor for, or in association with, groin pain was assessed by defining four levels of evidence (see table 1). ${ }^{17}$ A relationship was rated as positive when the risk estimate was increased. No relationship was identified when the effect estimate indicated no increased risk or a decreased risk of hip ROM or when it was reported to be statistically non-significant $(p>0.05)$ without reporting the risk estimate. Significant differences were based on means with SD and/or matching $95 \% \mathrm{CI}$. If a study provided neither of these two, any information on significant differences $(p<0.05)$ between the groups was used.

\section{RESULTS}

\section{Search results of this study}

The database search resulted in 784 studies of which 208 duplicates were removed. Screening of titles and abstracts was performed on the 576 remaining references for possible eligibility (see online supplementary Appendix 3 ) and 29 potentially 


\begin{tabular}{|c|c|c|}
\hline 1 & Strong evidence & $\begin{array}{l}\text { Consistent findings in multiple high-quality cohort and/or } \\
\text { case-control studies. }\end{array}$ \\
\hline 2 & Moderate evidence & $\begin{array}{l}\text { Consistent findings in multiple cohort and/or case- } \\
\text { control studies, of which only one is a high-quality study }\end{array}$ \\
\hline 3 & Some evidence & $\begin{array}{l}\text { Findings of one cohort or case-control study or } \\
\text { consistent findings in multiple cross-sectional studies, of } \\
\text { which at least one study is a high-quality study }\end{array}$ \\
\hline 4 & Inconclusive evidence & $\begin{array}{l}\text { Concerns all other cases-that is, consistent findings } \\
\text { in multiple low-quality, cross-sectional studies or } \\
\text { inconsistent findings in multiple studies. The evidence is } \\
\text { considered to be inconclusive if only one cross-sectional } \\
\text { study is available, regardless of the quality of this study }\end{array}$ \\
\hline
\end{tabular}

relevant studies were screened in full text. After checking cross-references, two additional studies were considered potentially relevant and included. ${ }^{10}{ }^{19}$ All citations (410 in total) from the seven relevant reviews ${ }^{3-9}$ were manually screened for potentially relevant references, which resulted in two additional references. ${ }^{20}$ The experts did not provide additional references. Finally, 11 of these 33 studies assessed in full text fulfilled the criteria and were included for data extraction (see figure 1).

\section{Study characteristics}

Seven prospective cohort and four case-control studies were included. Heterogeneity of definitions of groin pain and ROM was found (see table 2).

Table 3 presents the descriptives of the 11 studies included in this review.

The prospective cohort studies lasted for one or two consecutive playing seasons. The duration of the playing seasons depended on the sport and ranged from 4 months (Australian rules football/Gaelic football) to 6 months (ice hockey) or 9 months (soccer). The results of the included studies are presented in table 4.

\section{Methodological quality}

There were 35/146 (24\%) disagreements (See online supplementary appendix 4) on the risk of bias assessment, resulting in a moderate level of agreement of 0.43 (Cohen's $\kappa$ ). ${ }^{21}$ All but two $^{22} 23$ included studies had a high-quality score (table $5 \mathrm{~A}$ ). The total quality score of all studies included ranged from $29 \%$ to $92 \%$. The score of the seven prospective studies ranged from $58 \%$ to $92 \%$ and that of the four case-control studies from $29 \%$ to $71 \%$. Three studies did not report a possible conflict of interest, ${ }^{23-25}$ four studies reported a possible conflict ${ }^{1922} 2627$ and four studies reported that no conflict of interest ${ }^{28-31}$ was present.

The item scores for each study type are presented in table 5B. Scores $<1$ represent items with more negative than positive scores. These are considered as scoring relatively low.

The prospective studies had relatively low scores for items related to the standards of injury reporting, indicating the need to report how often injuries are registered during the surveillance period. This includes checking the injury criteria over time with limited interval periods (item 12). Additionally the injury criteria need to be clearly reported (ie, physical examination) (item 13).

The case-control studies perform relatively low on item (9), reporting whether or not the assessors were blinded to the disease status of the subjects and item (10) on assessing subjects before they developed symptoms or were injured. Item (16) on criteria for appropriate analysis (regression analysis) and item (17) on presenting probability data (odds) and item (18) on presenting confounding variables had relatively low scores.

Cochrane DSR, PUBMED, PEDRO search for review on topic prior to review $n=7$

CINAHL $n=62$, Sportdiscus $n=80$, EMBASE

$\mathrm{N}=382$, PUBMED $n=260$ (total $n=784$ )

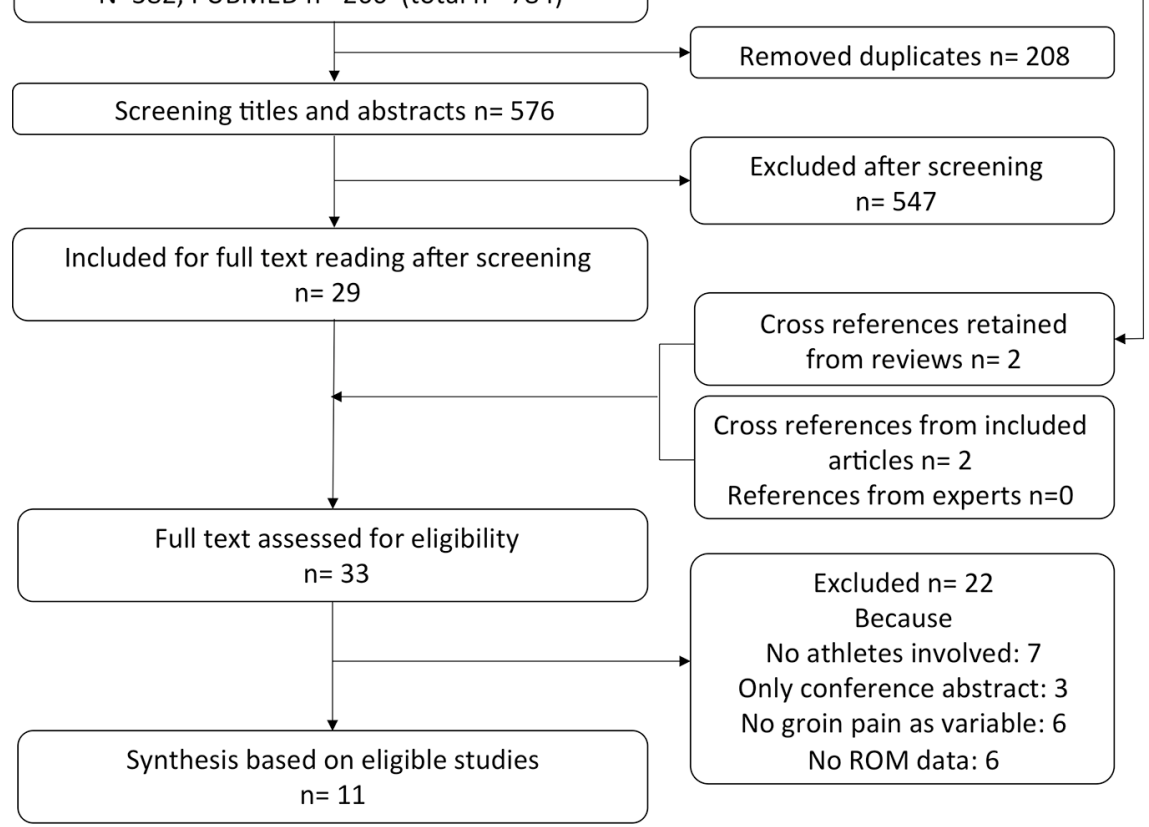

Figure 1 PRISMA flow diagram of the study search and selection procedure. DSR, database of systematic reviews; ROM, range of motion. 


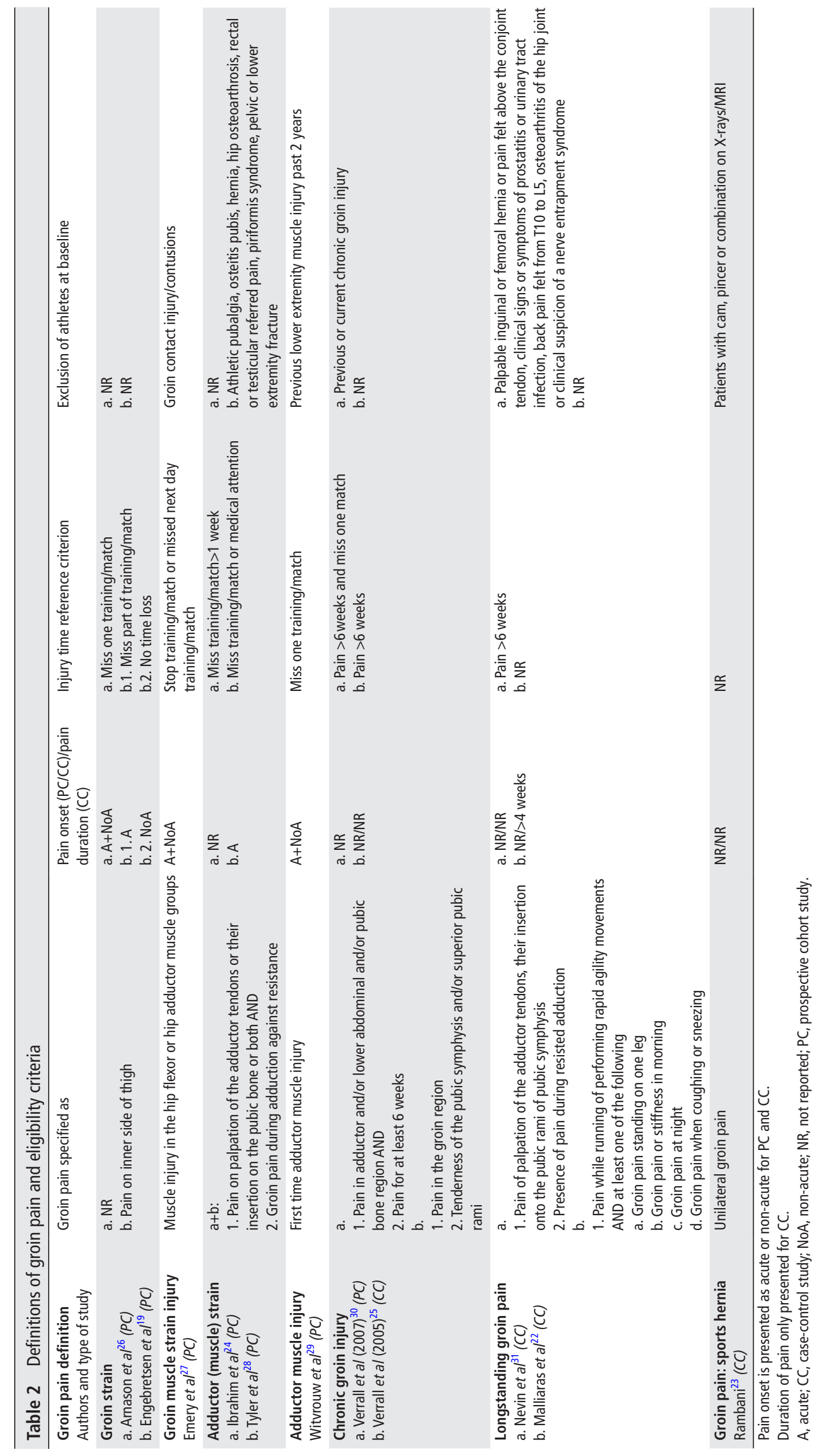




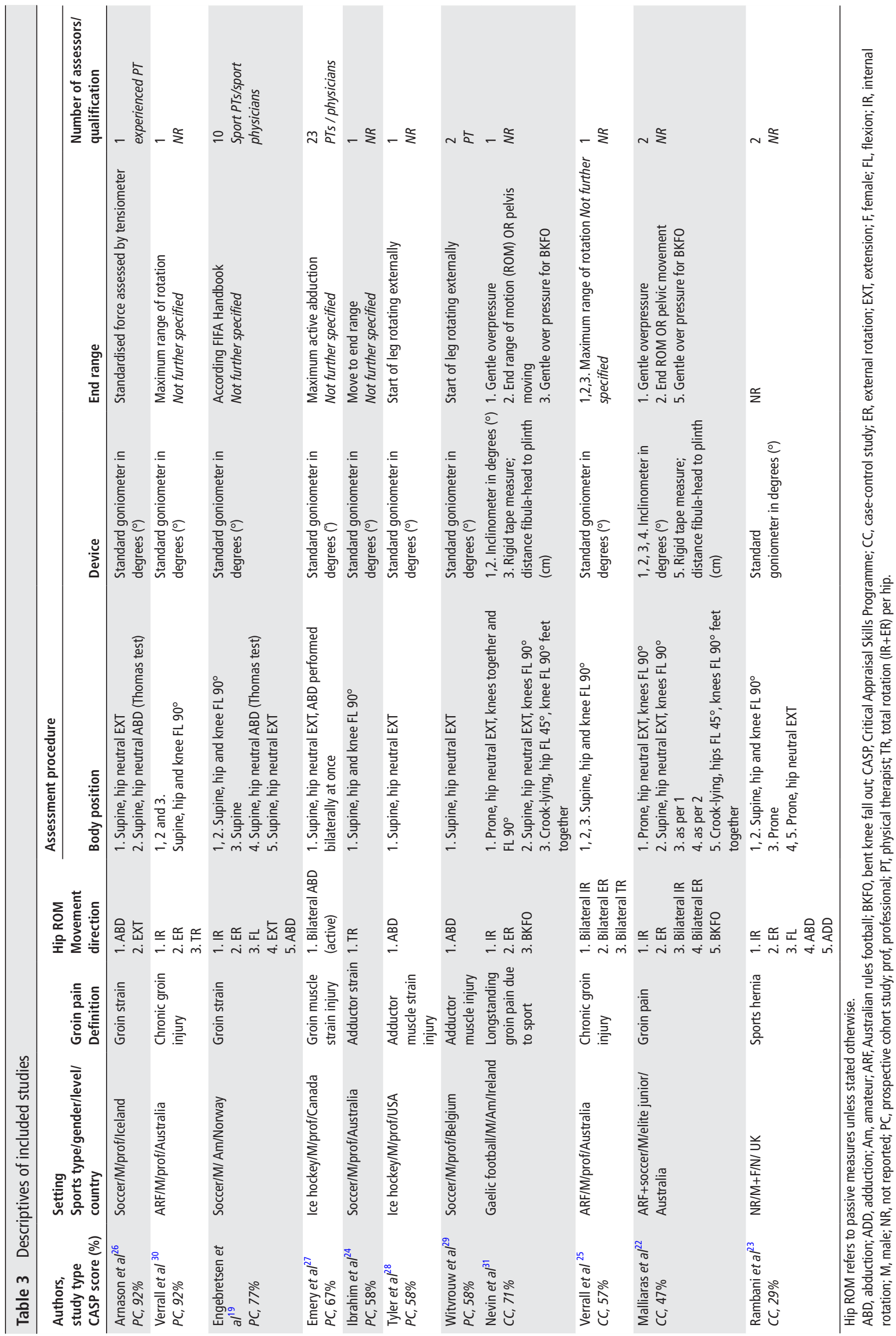




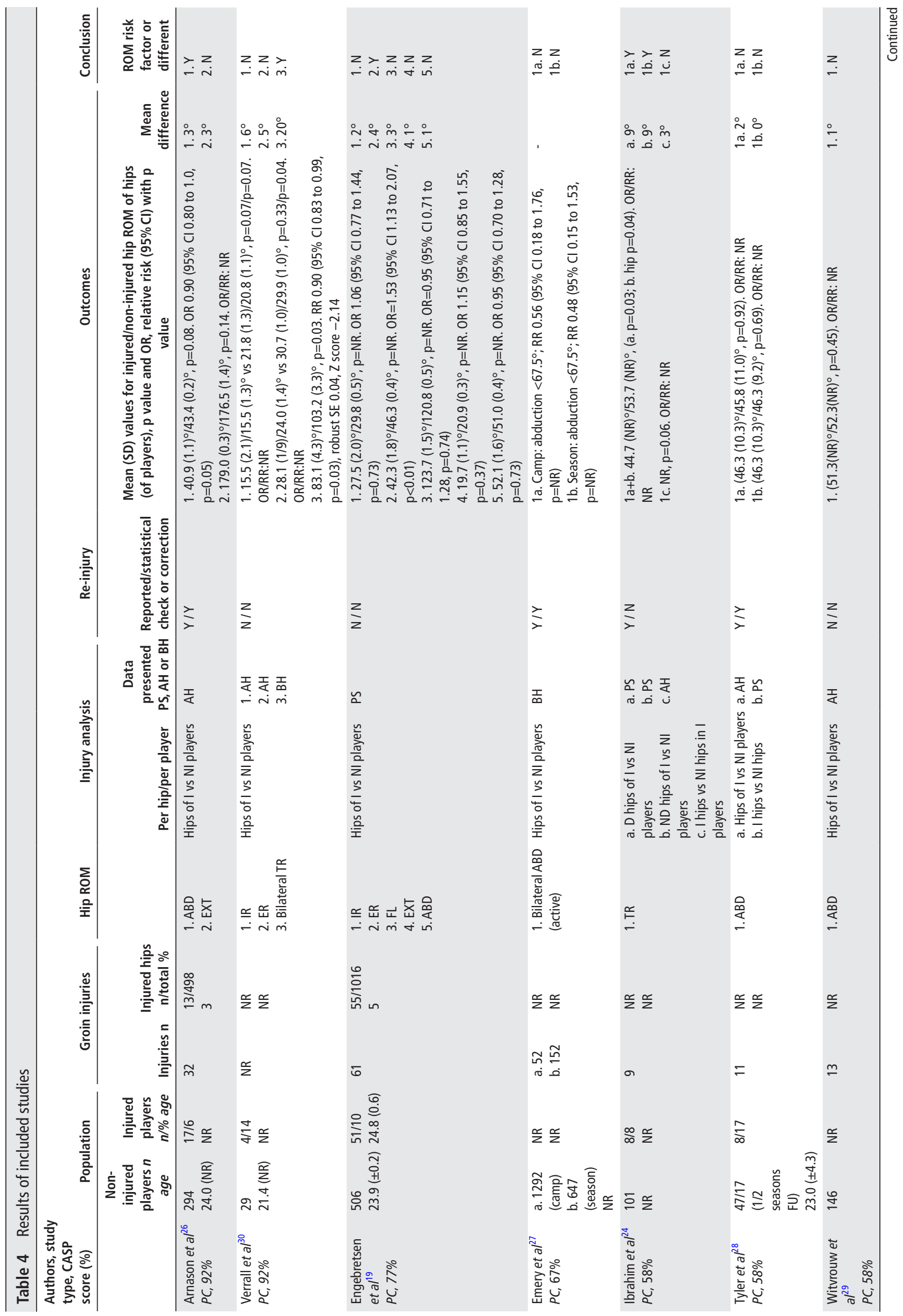

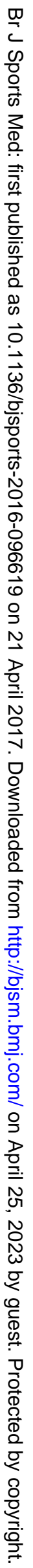




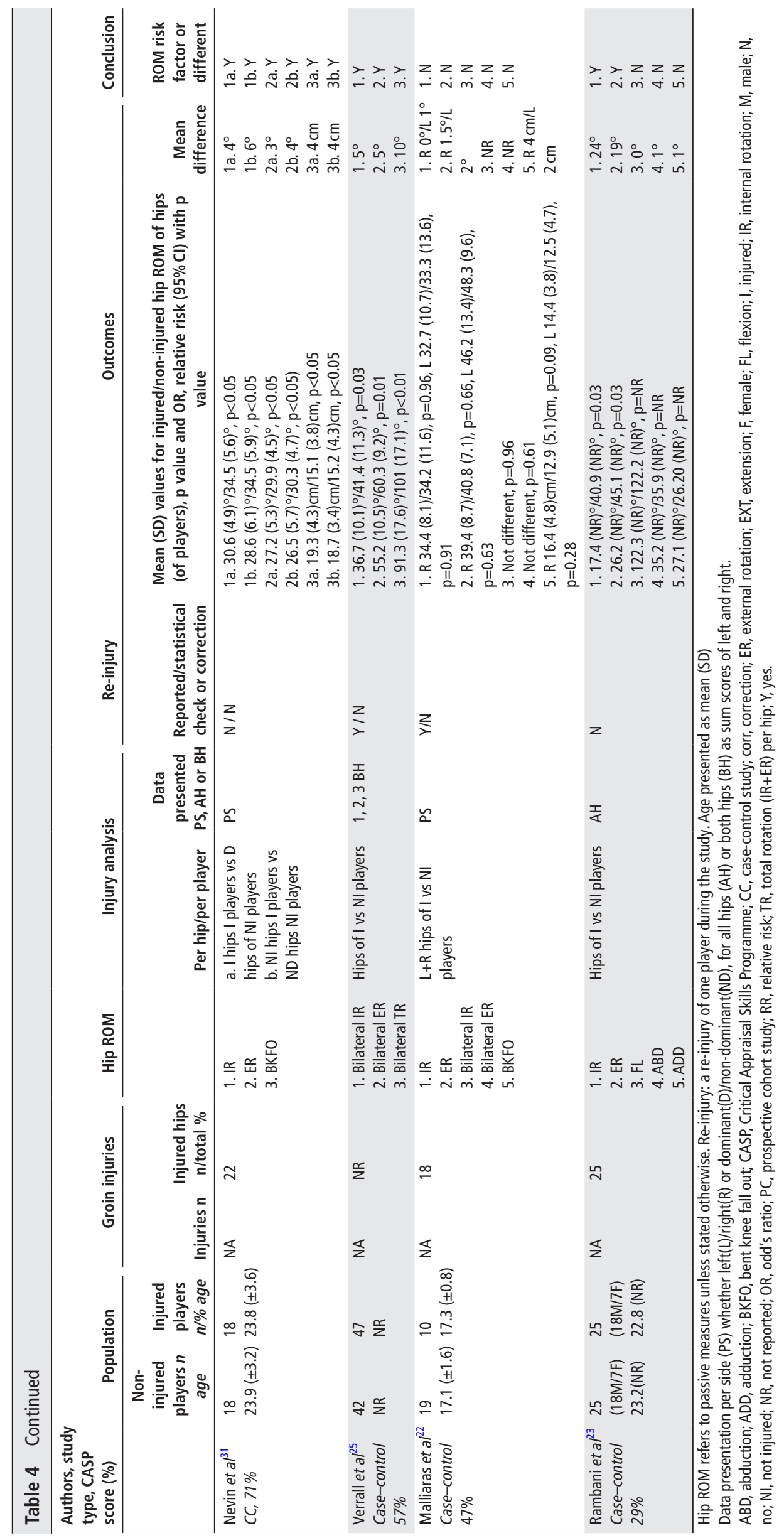

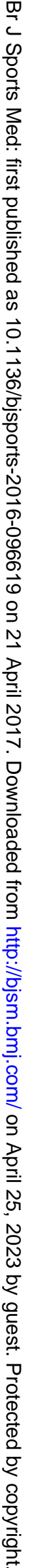




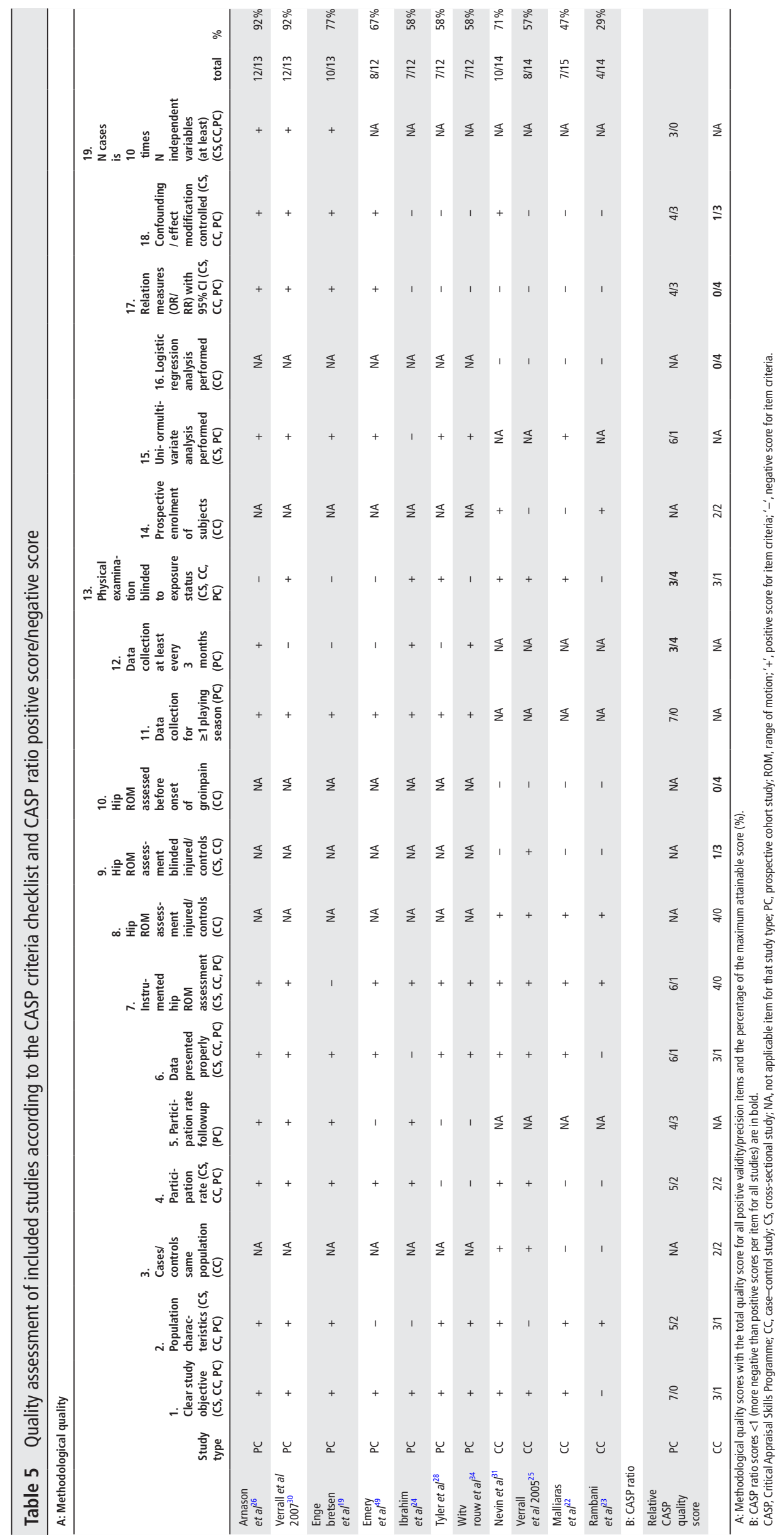

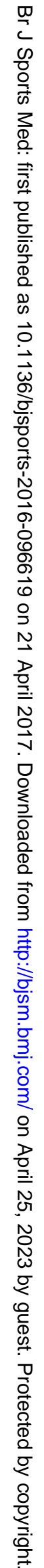


Table 6 Strength of evidence assessment whether ('for') or not ('against') all identified hip ROM measures have a relationship (risk of differentiating) with groin pain in athletes. (Findings are presented per hip unless otherwise stated.)

\begin{tabular}{|c|c|}
\hline Strength of evidence & Findings \\
\hline Strong & $\begin{array}{l}\text { Prospective RF studies: } \\
\text { For: lower TR of both hips (BH) (SHKF) })^{2430} \\
\text { Against: hip IR (SHKF) }{ }^{1930} \text { abduction }{ }^{196-29} \text { and } \\
\text { extension }^{1926}\end{array}$ \\
\hline Moderate & $\begin{array}{l}\text { Differentiates asymptomatic players from } \\
\text { symptomatic ones: } \\
\text { For: lower } \mathrm{IR}_{t}^{2325} \mathrm{ER}^{2325} \text { of } \mathrm{BH} \text { (SHKF) }\end{array}$ \\
\hline Some & $\begin{array}{l}\text { Prospective RF studies: } \\
\text { Against: TR per hip (SHKF), }{ }^{24} \text { hip flexion }{ }^{19} \text { and } \\
\text { bilateral abduction }{ }^{27} \\
\text { Differentiates asymptomatic players from } \\
\text { symptomatic ones: } \\
\text { For: lower TR of BH (SHKF) }{ }^{25} \\
\text { Against: combined (bilateral) hip IR (PHNE) and ER } \\
\text { (SHNE) }\end{array}$ \\
\hline Inconclusive & $\begin{array}{l}\text { Prospective RF studies: } \\
\text { Hip ER (SHKF) }{ }^{19} 30 \\
\text { Differentiates asymptomatic players from } \\
\text { symptomatic ones: } \\
\text { Hip IR (PHNE) }{ }^{22}{ }^{21} \mathrm{ER}(\mathrm{SHNE})^{2231} \text { and } \mathrm{BKFO}^{22} 31\end{array}$ \\
\hline $\begin{array}{l}\text { Not studied or single low } \\
\text { quality study }\end{array}$ & $\begin{array}{l}\text { Prospective RF studies: } \\
\text { Hip IR, ER, TR (all with neutral hip extension), BKFO } \\
\text { and adduction } \\
\text { Differentiates asymptomatic players from } \\
\text { symptomatic ones: } \\
\text { Hip extension, flexion, abduction and adduction. }\end{array}$ \\
\hline
\end{tabular}

BKFO, bent knee fall out; ER, external rotation; IR, internal rotation; PHNE, prone hip neutral extension; RF, risk factor; ROM, range of movement; SHKF, supine position with hip and knee flexed to $90^{\circ}$; SHNE, supine hip neutral extension; TR, total rotation.

\section{Overall strength of evidence}

Table 6 shows the strength of evidence for all ROM measures as risk factors, identified by prospective studies, or as differentiating factors as identified by case-control studies.

\section{DISCUSSION}

This systematic review included seven high quality prospective and four case-control studies (two high and two low quality) on the relationship between groin pain in athletes and hip ROM. Heterogeneous definitions for groin pain/injury and measurement techniques for hip ROM prevented data pooling. A strength-of-evidence synthesis showed that smaller $\left(<85^{\circ}\right)$ total rotational hip ROM (hips and knees $90^{\circ}$ flexed) is the most consistent risk factor for development of groin pain and differentiates athletes with groin pain from those without. However, the number of studies with homogeneous methods (two and one, respectively) is limited.

\section{Heterogeneity in terminology and definitions}

Heterogeneous terminology and definitions, as identified in the included studies, has also been highlighted in a Delphi study among groin pain experts. ${ }^{32}$ There was also large variability in the injury and time-loss criteria, reflecting different stages of the injury spectrum. ${ }^{33}$ This ranged from inclusion of players with pain who were still able to play $^{19}$ to players with a first-time groin time-loss injury ${ }^{34}$ or those with time loss and pain $>6$ weeks. ${ }^{30}$ The magnitude of time loss ranged considerably from missing part of one match to missing $>1$ week of play. ${ }^{24}$ Altering thresholds for injury definition affects injury prevalence and incidence, which will influence the results and interpretation of the study findings.

\section{ROM measures}

There are important concerns about heterogeneity and measurement properties to consider when interpreting these data.

\section{Heterogeneity}

Even though 11 studies report hip ROM and groin pain, the strength-of-evidence assessment, indicating total rotational ROM measure as being related to groin pain, was based on only two studies. Other studies could not be included in this synthesis, owing to heterogeneous hip ROM measures, different assessment methods ${ }^{35}$ and whether or not the analysis was performed for each hip ${ }^{1922} 24283031$ or for combined (either internal rotation (IR) or external rotation (ER) ${ }^{2530}$ or for bilateral ${ }^{23-30}$ ) ROM values.

\section{Validity and reliability of hip ROM measures}

When measuring rotational hip ROM, the validity will be influenced by the measurement protocol. One specific element is the criterion used to determine end ROM. Overestimation is possible if the measurements are not conducted in a single plane, or if compensation from the pelvis and lower back are permitted. ${ }^{35}$ End ROM criteria are generally under-reported, 19 23-25 2730 which limits assessment of study validity.

A large number of raters (a range of 1-23 raters was found) will result in increased rater variability, and this reduces measurement reliability, ${ }^{36}{ }^{37}$ and increases the standard error of measurement (SEM) and minimal detectable change (MDC) ${ }^{22}$ values for hip ROM measures. Using a single examiner can deal with this, but this limits extrapolation of the findings to different settings. Electronic assessments of forces applied may be useful to increase reliability ${ }^{38}$ but this was performed in only one of the studies. ${ }^{26}$ Reduction of compensatory movements and applying standardised force with a specially developed examination chair has been reported to strongly increase the reliability of hip ROM assessment. ${ }^{39}$

\section{Minimal detectable change}

To detect true differences or changes in ROM-that is, changes that are not the result of measurement error, differences must at least equal or exceed the MDC. No studies in this review dealt with this topic. For IR and ER (hips and knees $90^{\circ}$ flexed) assessed with a goniometer, the SEM (intra-rater) was previously reported to be $2^{\circ}$ and $3^{\circ} .{ }^{38}$ Computing the MDC, based on SEM values according the formula $\mathrm{MDC}=(1.96 \times \mathrm{SEM} \times \sqrt{ } 2)$, reveals MDCs for both IR and ER of $7^{\circ}$. For assessment with hips in neutral extension the SEM (intra-rater) is $2^{\circ}$ and $4^{\circ}, 22$ resulting in MDC for IR of $6^{\circ}$ and ER of $11^{\circ}$. The differences found for rotational ROM often exceed the SEM, but not the MDC. Thus, the available evidence suggests that ROM is not an appropriate screening measure for predicting groin pain. Future studies could combine data from larger cohorts to improve the accuracy of the estimation of risk. However, to pool such studies, homogeneity of the items previously discussed in this paper is a prerequisite.

\section{What to consider when performing new studies?}

We suggest that future studies should consider examining and reporting all ROM measures available for each hip either unilaterally or bilaterally and for $\mathrm{BH}$ (combined). Appropriate stabilisation of the pelvis, a clear definition of end ROM and forces 
applied should be used and described in detail. The number of raters should be as low as possible.

\section{ROM and groin pain}

The evidence from this review does not support a relationship between hip ROM and groin pain, which is at odds with clinical perceptions. It has been hypothesised that restricted hip rotations induce increased stress over the symphysis and surrounding soft tissues. ${ }^{102540}$ One cadaver study ${ }^{11}$ observed that the presence of cam morphology, which is associated with decreased internal rotation, ${ }^{41}$ increased the shear forces and rotational movement of the symphysis. Yet, no in vivo validation has been performed of the effects of lower hip ROM measures. A recent paper, published after the search period of this review, showed that hip ROM, when assessed in a sport-specific way, is lower on the injured side in players with unilateral longstanding adductor-related groin pain. ${ }^{42}$ It was postulated that this negatively affects biomechanical characteristics ${ }^{42}$ and hinders adequate energy transfer between body segments ${ }^{43}$ during sporting tasks, resulting in supraphysiological tissue loading.

\section{Confounders}

Previous injury is a risk factor for re-injury. ${ }^{3}$ Two prospective studies accounted for this by recording re-injuries ${ }^{29} 30$ or correcting for their presence in the analyses, whereas others did not. ${ }^{19242628}$

Age is a risk factor for groin pain. ${ }^{3}$ Some prospective studies reported participants' ages for the studied ${ }^{1926-28}$ and injured ${ }^{19} 27$ populations and accounted for age in the analyses, ${ }^{26} 2730$ and two ${ }^{19} 30$ corrected for this association when indicated. However, others do not report age. ${ }^{24}{ }^{29} \mathrm{ROM}$ is related to age and has also been shown to decrease in older players and in those playing at higher levels. $^{44}$

When ER and/or IR are studied in isolation, they are not risk factors for the development of groin pain. However, when combined (summated) to give total rotation, there is an increased risk when total rotation is lower. Individual anatomical differences between version of the femoral neck, resulting in greater or smaller ER or IR, may be confounders. ${ }^{45}$

Smaller internal rotation has been associated with the presence of cam morphology. ${ }^{41}$ This morphological appearance may be a confounder as it is highly prevalent in athletes, but the reported prevalence estimates have a high risk of bias. ${ }^{46}$

Therefore, future studies should report and correct for previous injury, age and presence of cam morphology, as these are recognised confounders for groin pain and ROM.

\section{LIMITATIONS}

We identified many factors that might influence the outcome of the selected studies, such as reporting and consistency of measurement techniques, which were generally poorly or not reported at all. There were also many differences in the definitions of 'groin pain' and 'injury'. This combination of poor reporting and use of heterogeneous injury definitions and measurement methods prevented a comparison of many study findings. This limited our ability to group studies to provide higher levels of evidence.

When consulting the current strength of evidence assessment, 'strong evidence' may be an 'overqualification' in our review. The strength of evidence method used means that having two high-quality studies qualifies as 'strong evidence'. For some readers 'strong evidence' may intuitively refer to a larger body of evidence. A general limitation threatening the validity of this, like any other review, is that non-published data may exist together with publication bias. A study reporting negative findings - that is, no relationship between ROM and groin pain, may be less likely to be published. We used SPORTDiscus and contacted experts in the field in an effort to find other papers. A more comprehensive grey literature search might have helped. All but one of the studies were on male athletes and thus, information from this review cannot be extrapolated to female athletes, leaving space for new research.

\section{When you are a clinician, seeing patients with groin pain you may consider}

- Single-observer ROM assessment, when performed with measurement devices, can detect changes in hip ROM over time. However, the changes may only be true if they exceed $7^{\circ}$ for either IR or ER (hip and knee flexed).

- Considering that total rotational ROM of both hips is lower in athletes with groin pain, improving it as part of treatment should be considered. However, as the differences found are generally small, this should not be the only intervention. It is also difficult to identify which patients may benefit.

- Screening for hip ROM to prevent groin injury is unlikely to detect an athlete at risk. When a large deficit is found, prevention can be considered, although what this should entail remains unclear.

\section{When you perform research on hip ROM in athletes with groin pain and want to contribute to the existing knowledge you should consider}

- Using clear and generally accepted injury definitions and terminology; ${ }^{147} 48$

- Reporting the physical examination findings of injury and ROM measurement techniques comprehensively (eg, both IR, ER and summated measures) and providing data on measurement properties (eg, SEM and MDC);

- Blinding of assessors for participant's injury status and injured side(s);

- Presenting risk estimates (absolute risk/OR/risk ratio), with and without confounding variables.

\section{CONCLUSION}

There is strong evidence that lower total hip ROM of both hips is a risk factor for the development of groin pain. There is strong evidence that internal rotation, abduction and extension are not risk factors for the development of groin pain. Screening for hip ROM is unlikely to correctly identify an athlete at risk because of the small ROM differences found, which were lower than the known measurement errors.

What is already known on this topic and what this study adds

- No information exists on how to apply the available information on hip range of motion (ROM) and groin pain in athletes.

- There is strong evidence supporting the statement that smaller total rotation $\left(<85^{\circ}\right)$ of both hips at a pre-season screening increases the risk of developing groin pain other ROM determinants do not.

- Hip ROM assessment does not allow correct identification of an athlete at risk of groin pain. 


\section{Author affiliations}

'Manual Therapy and Sports Rehabilitation, Physiotherapy Utrecht Oost, Utrecht, The Netherlands

${ }^{2}$ Academic Center for Evidence based Sports Medicine (ACES), AMC, Amsterdam, The Netherlands

${ }^{3}$ Engelaar Sports Physiotherapy, Doetinchem, The Netherlands

${ }^{4}$ Division of Exercise Science and Sports Medicine, University of Cape Town, Cape Town, South Africa

${ }^{5}$ Dutch Center for Allied Health Care, Amersfoort, The Netherlands

${ }^{6}$ Master Physical Therapy in Sports, Avans+ Improving Professionals, Breda, The

Netherlands

${ }^{7}$ Department of Orthopedic Surgery, Academic Medical Center Amsterdam, Amsterdam, The Netherlands

${ }^{8}$ Manual Therapy and Sports Rehabilitation, Physiotherapy Dukenburg Nijmegen, Nijmegen, The Netherlands

${ }^{9}$ School of Sports \& Nutrition, Amsterdam University of Applied Sciences, Amsterdam, The Netherlands

${ }^{10}$ Codarts University of the arts, Rotterdam, The Netherlands

${ }^{11}$ Department of Sports Medicine, Aspetar hospital, Doha, Qatar

Contributors IT: Conception and design. Data acquisition, analysis and interpretation of data. Drafting the article. Revising it critically for important intellectual content and final approval of the version to be published. LE: Conception and design. Data acquisition, analysis and interpretation of data. Drafting the article. Final approval of the version to be published. VG: Conception and design. Critically assisting in interpretation of data. Revising the article critically for important intellectual content and final approval of the version to be published. MB: Conception and design. Critically assisting in interpretation of data. Revising the article critically for important intellectual content and final approval of the version to be published. SVDH: Data acquisition. Revising the article critically and final approval of the version to be published. RL: Revising the article critically and final approval of the version to be published. GK: Revising the article critically for important intellectual content and final approval of the version to be published. JS: Revising the article critically for important intellectual content and final approval of the version to be published. AW: Help in preparation of the manuscript. Revising the article for critical intellectual content. Interpretation of data and final approval of the version to be published.

\section{Competing interests None declared.}

Provenance and peer review Not commissioned; externally peer reviewed.

Open Access This is an Open Access article distributed in accordance with the Creative Commons Attribution Non Commercial (CC BY-NC 4.0) license, which permits others to distribute, remix, adapt, build upon this work non-commercially, and license their derivative works on different terms, provided the original work is properly cited and the use is non-commercial. See: http://creativecommons.org/ licenses/by-nc/4.0/

(c) Article author(s) (or their employer(s) unless otherwise stated in the text of the article) 2017. All rights reserved. No commercial use is permitted unless otherwise expressly granted.

\section{REFERENCES}

1 Weir $A$, Brukner $P$, Delahunt $E$, et al. Doha agreement meeting on terminology and definitions in groin pain in Athletes. Br J Sports Med 2015;49:768-74.

2 Ekstrand J, Gillquist J. The avoidability of soccer injuries. Int J Sports Med 1983:4:124-8.

3 Whittaker JL, Small C, Maffey L, et al. Risk factors for groin injury in sport: an updated systematic review. Br J Sports Med 2015;49:803-9.

4 Ryan J, DeBurca N, Mc Creesh K. Risk factors for groin/hip injuries in field-based sports: a systematic review. Br J Sports Med 2014;48:1089-96.

5 Mosler AB, Agricola R, Weir A, et al. Which factors differentiate Athletes with hip/groin pain from those without? A systematic review with meta-analysis. Br J Sports Med 2015:49:810

6 Maffey L, Emery C. What are the risk factors for groin strain injury in sport? A systematic review of the literature. Sports Med 2007;37:881-94.

7 Hrysomallis C. Injury incidence, risk factors and prevention in australian rules football. Sports Med 2013;43:339-54

8 Hrysomallis C. Hip adductors' strength, flexibility, and injury risk. J Strength Cond Res 2009:23:1514-7.

9 Dallinga JM, Benjaminse A, Lemmink KA. Which screening tools can predict injury to the lower extremities in team sports?: a systematic review. Sports Med 2012;42:791-815

10 Williams JG. Limitation of hip joint movement as a factor in traumatic osteitis pubis. Br J Sports Med 1978;12:129-33.

11 Birmingham PM, Kelly BT, Jacobs R, et al. The effect of dynamic femoroacetabular impingement on pubic symphysis motion: a cadaveric study. Am J Sports Med 2012;40:1113-8.
12 Esteve E, Rathleff MS, Bagur-Calafat C, et al. Prevention of groin injuries in sports: a systematic review with meta-analysis of randomised controlled trials. $\mathrm{Br}$ J Sports Med 2015;49:1-8.

13 Taylor BN, Thompson A, Cd Mol Kg AK, et al. The international system of units (SI) NIST special publication 3302008 edition. 2008 ed. Gaithersburg, MD 20899: Department of Commerce, United States of America, 2008. http://physics.nist.gov/ Pubs/SP330/sp330.pdf

14 van der Worp $H$, van Ark M, Roerink S, et al. Risk factors for patellar tendinopathy: a systematic review of the literature. Br J Sports Med 2011;45:446-52.

15 Bongers PM, Kremer AM, ter Laak J. Are psychosocial factors, risk factors for symptoms and signs of the shoulder, elbow, or hand/wrist?: a review of the epidemiological literature. Am J Ind Med 2002;41:315-42.

16 van der Windt DA, Thomas E, Pope DP, et al. Occupational risk factors for shoulde pain: a systematic review. Occup Environ Med 2000;57:433-42.

17 Ariëns GA, van Mechelen W, Bongers PM, et al. Psychosocial risk factors for neck pain: a systematic review. Am J Ind Med 2001;39:180-93

18 Shea BJ, Grimshaw JM, Wells GA, et al. Development of AMSTAR: a measurement too to assess the methodological quality of systematic reviews. BMC Med Res Methodol 2007:7:10.

19 Engebretsen AH, Myklebust G, Holme I, et al. Intrinsic risk factors for groin injuries among male soccer players: a prospective cohort study. Am J Sports Med 2010;38:2051-7.

20 Merrifield HH, Cowan RF. Groin strain injuries in ice hockey. J Sports Med 1973;1:41-2.

21 McHugh ML. Interrater reliability: the kappa statistic. Biochem Med 2012;22:276-82.

22 Malliaras P, Hogan A, Nawrocki A, et al. Hip flexibility and strength measures: reliability and association with athletic groin pain. Br J Sports Med 2009;43:739-44.

23 Rambani R, Hackney R. Loss of range of motion of the hip joint: a hypothesis for etiology of sports hernia. Muscles Ligaments Tendons J 2015;5:29-32.

24 Ibrahim A, Murrell GAC, Knapman P. Adductor strain and hip range of movement in male professional soccer players. J Orthop Surg 2007;15:46-9.

25 Verrall GM, Hamilton IA, Slavotinek JP, et al. Hip joint range of motion reduction in sports-related chronic groin injury diagnosed as pubic bone stress injury. J Sci Med Sport 2005;8:77-84.

26 Arnason A, Sigurdsson SB, Gudmundsson A, et al. Risk factors for injuries in football. Am J Sports Med 2004;32:5S-16.

27 Emery CA, Meeuwisse WH. Risk factors for groin injuries in hockey. Med Sci Sports Exerc 2001;33:1423-33.

28 Tyler TF, Nicholas SJ, Campbell RJ, et al. The association of hip strength and flexibility with the incidence of adductor muscle strains in professional ice hockey players. Am J Sports Med 2001;29:124-8.

29 Witvrouw E, Danneels L, Asselman P, et al. Muscle flexibility as a risk factor for developing muscle injuries in male professional soccer players a prospective study. Am J Sports Med 2003;31:41-6.

30 Verrall GM, Slavotinek JP, Barnes PG, et al. Hip joint range of motion restriction precedes athletic chronic groin injury. J Sci Med Sport 2007:10:463-6.

31 Nevin F, Delahunt E. Adductor squeeze test values and hip joint range of motion in gaelic football Athletes with longstanding groin pain. J Sci Med Sport 2014;17:155-9.

32 Weir A, Hölmich P, Schache AG, et al. Terminology and definitions on groin pain in Athletes: building agreement using a short delphi method. Br J Sports Med 2015;49:825-7.

33 Tak I, Glasgow P, Langhout $R$, et al. Hip range of motion is lower in professional soccer players with hip and groin symptoms or previous injuries, independent of cam deformities. Am J Sports Med 2016:44:682-8.

34 Witvrouw E, Danneels L, Asselman P, et al. Muscle flexibility as a risk factor for developing muscle injuries in male professional soccer players. A prospective study. Am J Sports Med 2003:31:41-6.

35 van Trijffel E, van de Pol RJ, Oostendorp RA, et al. Inter-rater reliability for measurement of passive physiological movements in lower extremity joints is generally low: a systematic review. J Physiother 2010;56:223-35.

36 Aalto TJ, Airaksinen 0, Härkönen TM, et al. Effect of passive stretch on reproducibility of hip range of motion measurements. Arch Phys Med Rehabil 2005;86:549-57.

37 Cibere J, Thorne A, Bellamy N, et al. Reliability of the hip examination in osteoarthritis: effect of standardization. Arthritis Rheum 2008;59:373-81.

38 Nussbaumer S, Leunig M, Glatthorn JF, et al. Validity and test-retest reliability of manual goniometers for measuring passive hip range of motion in femoroacetabular impingement patients. BMC Musculoskelet Disord 2010;11:194.

39 Reichenbach $S$, Jüni $P$, Nüesch $E$, et al. An examination chair to measure internal rotation of the hip in routine settings: a validation study. Osteoarthritis Cartilage 2010;18:365-71.

40 Fricker PA. Reviews management of groin. Br J Sports Med 1997:31:97-101.

41 Reichenbach S, Jüni $\mathrm{P}$, Werlen $\mathrm{S}$, et al. Prevalence of cam-type deformity on hip magnetic resonance imaging in young males: a cross-sectional study. Arthritis Care Res 2010;62:1319-27.

42 Tak IJ, Langhout RF, Groters S, et al. A new clinical test for measurement of lower limb specific range of motion in football players: design, reliability and reference findings 
in non-injured players and those with long-standing adductor-related groin pain. Phys Ther Sport 2017;23:67-74.

43 Shan G, Westerhoff P. Full-body kinematic characteristics of the maximal instep soccer kick by male soccer players and parameters related to kick quality. Sports Biomech 2005;4:59-72.

44 Manning C, Hudson Z. Comparison of hip joint range of motion in professional youth and senior team footballers with age-matched controls: an indication of early degenerative change? Phys Ther Sport 2009;10:25-9.

45 Chadayammuri V, Garabekyan T, Bedi A, et al. Passive hip range of motion predicts femoral torsion and acetabular version. J Bone Joint Surg Am 2016;98:127-34.
46 Dickenson E, Wall PDH, Robinson B, et al. Prevalence of cam hip shape morphology: a systematic review. Osteoarthritis Cartilage 2016;24:949-61.

47 Delahunt $\mathrm{E}$, Thorborg K, Khan KM, et al. Minimum reporting standards for clinical research on groin pain in Athletes. Br J Sports Med 2015;49:775-81.

48 Fuller CW, Ekstrand J, Junge A, et al. Consensus statement on injury definitions and data collection procedures in studies of football (soccer) injuries. Scand J Med Sci Sports 2006;16:83-92.

49 Emery CA, Meeuwisse WH. Risk factors for groin injuries in hockey. Med Sci Sports Exerc 2001;33:1423-33. 